\title{
An Overview of High-Efficacy Drugs for Multiple Sclerosis: Gulf Region Expert Opinion
}

\author{
Raed Alroughani · Jihad Said Inshasi · Dirk Deleu · Jasem Al-Hashel • \\ Mustafa Shakra - Osama Robin Elalamy · Ahmed Osman Shatila • \\ Abdullah Al-Asmi · Isa Al Sharoqi • Beatriz Garcia Canibano • \\ Amir Boshra
}

Received: October 16, 2018 / Published online: March 15, 2019

(c) The Author(s) 2019

\section{ABSTRACT}

This article discusses the opinions of the multiple sclerosis (MS) experts in the Gulf region on the use of high-efficacy disease-modifying drugs (DMDs; natalizumab, fingolimod, alemtuzumab, cladribine tablets, and ocrelizumab) in clinical practice. The experts reviewed the current literature including pivotal clinical trials and meta-analyses for high-efficacy DMDs, supplemented by the expert opinions on the usage of these DMDs in clinical practice. Several

Enhanced Digital Features To view enhanced digital features for this article, go to https://doi.org/10.6084/ m9.figshare.7687670.

R. Alroughani $(\bowtie)$

Division of Neurology, Department of Medicine, Amiri Hospital, Sharq, Kuwait

e-mail: alroughani@gmail.com

J. S. Inshasi

Neurology, Rashid Hospital, DMC, DHA, Dubai, UAE

D. Deleu

Department of Neurology, Hamad Medical

Corporation, Doha, Qatar

J. Al-Hashel

Department of Neurology, Ibn Sina Hospital, Kuwait City, Kuwait

M. Shakra

Department of Neurology, Sheikh Khalifa Medical

City, Abu Dhabi, UAE criteria were discussed by the panel based on different efficacy, safety, and convenience attributes. The panel concluded that all the DMDs available for the treatment of MS have benefits and risks, which should be considered while discussing the treatment plan with the patient. It is important to have a personalized approach based on the risk-benefit assessment for each case. Common considerations while choosing treatments include effectiveness, side effects/safety, and convenience/route of administration.

Funding: Merck Serono Middle East FZ LTD.

O. R. Elalamy

Hamad Medical Corporation, Weill Cornell Medical College, Ar Rayyān, Qatar

A. O. Shatila

Al Mafraq Hospital, Abu Dhabi, UAE

A. Al-Asmi

Department of Medicine, SQUH, Seeb, Sultanate of Oman

I. Al Sharoqi

Salmaniya Medical Complex, Manama, Bahrain

B. G. Canibano

Hamad Medical Corporation, Doha, Qatar

A. Boshra

Merck Serono Middle East FZ LTD, Dubai, UAE 
Keywords: Disease-modifying drugs; Expert opinion; Gulf region; Multiple sclerosis; Neuroimmunology

\section{INTRODUCTION}

Multiple sclerosis (MS) is an inflammatory demyelinating disorder in which the myelin sheaths surrounding nerve fibers in the central nervous system (CNS) are damaged. The immune-mediated damage disrupts communication between the brain and the rest of the body, leading to symptoms such as numbness, visual dysfunction, weakness, gait difficulty, bowel and bladder dysfunction, and cognitive impairment. Relapsing/remitting disease course is the most common (85\%), with isolated attacks of new or increasing neurological symptoms [29]. The primary progressive form, seen in around $10-15 \%$ of MS patients, is characterized by worsening neurological function from symptom onset, without relapses or remission [43]. Among patients with relapsing/ remitting MS (RRMS), there is a subset of patients with highly active MS. Such patients are characterized by frequent relapses with incomplete recovery, high burden of radiological lesions, and rapid disability worsening $[32,42]$.

The exact cause of MS is still unknown; however, genetic and environmental factors are believed to play a role. Multiple mechanisms of immune-mediated injury to myelin and oligodendrocytes have been proposed, such as cytokine-mediated injury, complement-mediated injury, antibody-mediated cytotoxicity, and direct injury to oligodendrocytes by $\mathrm{CD} 4+$ and CD8+ T cells [36]. Since T and B lymphocytes and cytokines play important roles in the pathogenesis of MS, immune therapies targeting these lymphocytes and cytokines can achieve better treatment outcomes. However, therapies differ in their ability to penetrate the blood brain barrier and act locally on inflammation and neurodegeneration in the CNS compartment $[1,6]$. The search for new treatments aims at increasing benefits by increasing the anti-inflammatory activity in the CNS compartment while reducing treatment- limiting adverse effects and high treatment burden $[7,47,51]$.

In the past 25 years or so, many diseasemodifying drugs (DMDs) have been approved for RRMS. Such DMDs include interferon-beta, glatiramer acetate, teriflunomide, dimethyl fumarate, natalizumab, fingolimod, alemtuzumab, cladribine tablets, and ocrelizumab. These drugs exert their anti-inflammatory effects through various mechanisms [35].

The objective of this article is to discuss opinions of MS experts in the Gulf region on the use of high-efficacy DMDs in the clinical practice. This discussion was focused on the following high-efficacy DMDs: natalizumab, fingolimod, alemtuzumab, cladribine tablets, and ocrelizumab. Nine experts from the Gulf region with expertise in MS treatment were part of the discussion sessions. The experts were selected based on their years of expertise in managing MS patients.

\section{OVERVIEW OF HIGH-EFFICACY DMDS USED IN RRMS}

\section{Natalizumab}

Natalizumab was the first monoclonal antibody approved to treat MS (in the United States [USA] in 2004 and in the European Union [EU] in 2006). Natalizumab prevents the migration of immune cells into the CNS by selectively binding to and inhibiting the very late antigen-4 (VLA-4) integrins [41]. Natalizumab is indicated as monotherapy in adults with highly active RRMS. It is generally recommended for patients who have had an inadequate response to, or are unable to tolerate, an alternate MS therapy [49]. Natalizumab is administered as an intravenous (IV) infusion once every 4 weeks [49]. In a phase III trial in patients with RRMS (AFFIRM trial), natalizumab reduced the annualized relapse rate (ARR) by $68 \%(p<0.001)$ and the disability progression rate by $42 \%(p<0.001)$ compared with placebo over 2 years [39]; in another trial, it significantly improved magnetic resonance imaging (MRI) outcomes versus placebo over 2 years [33]. 
Natalizumab is generally well-tolerated; however, it increases the risk of progressive multifocal leukoencephalopathy (PML), an opportunistic viral infection of the brain, that usually causes death (23\% mortality rate) or severe disability $[46,49]$. By the end of 2017, around 756 people (out of over 180,000 people across the world taking natalizumab) had developed PML. It is therefore recommended that patients treated with natalizumab should be regularly screened for the risk of PML development using clinical vigilance, periodic MRI brain, and anti-John Cunningham virus (JCV) antibody. Presence of anti-JCV antibodies, prolonged treatment duration, and previous use of immunosuppressive therapy increase the risk of PML [19]. In patients who are at high risk for the development of PML, discontinuation of natalizumab is considered; however, this may trigger severe rebound with clinical and radiological worsening. Therefore, close monitoring with a short washout phase is recommended after natalizumab withdrawal [19]. Clinically significant liver injury has been reported in patients treated with natalizumab in the post-marketing setting [3]. Other potential serious risks associated with natalizumab include infusion reactions, and rare, serious opportunistic infections, especially PML. Appropriate patient selection by a thorough understanding of individual risk factors for PML and other adverse events can prove beneficial for optimizing treatment with natalizumab in RRMS patients [46].

\section{Fingolimod}

Fingolimod is the first oral drug for MS, approved in the USA in 2010 and in the EU in 2011. It is an immunosuppressive agent that blocks the egress from the lymph nodes to the CNS by its action on sphingosine 1-phosphate (S1P) receptors [4, 5, 31, 38]. However, fingolimod does not affect lymphocyte function [31]. Fingolimod has been shown to be superior to placebo (over 2 years) and interferon $\beta-1$ a (IFN $\beta-1 \mathrm{a}$; over 1 year) in terms of reduction in the ARR and brain lesions in RRMS patients $[8,23]$. Moreover, fingolimod was superior to placebo for reducing the risk of disability progression; however, it was equivalent to IFN $\beta$ 1a [8].

The most common adverse events reported with fingolimod in clinical trials and in a realworld setting include infections such as influenza and sinusitis [13, 15]. Cases of bradyarrhythmia and atrioventricular (AV) blocks have been reported in patients treated with fingolimod; therefore, patients should be monitored during treatment initiation [50]. On having to restart fingolimod after discontinuation for more than 14 days after the first month of treatment, similar monitoring is recommended [15]. Macular edema has been reported in patients treated with fingolimod; hence, a follow up ophthalmological examination is recommended 4-6 months after initiation of treatment [24]. In patients with pre-existing heart conditions, or in diabetic patients who may at higher risk of developing macular edema, benefits of fingolimod should be weighed against its risks before initiating fingolimod therapy. Risk of PML is low with fingolimod; of the more than 200,000 fingolimodtreated patients worldwide, as of August 2017, 15 patients developed PML in the absence of natalizumab treatment in the preceding 6 months [2]. Cases of disease reactivation have been reported in patients who discontinued fingolimod [44].

A meta-analysis of 25 real-world studies of fingolimod found that an average of $82 \%$ of patients continued with fingolimod treatment for 1 year [22], which indicates good treatment adherence.

\section{Alemtuzumab}

Alemtuzumab is a recombinant humanized monoclonal antibody, approved for RRMS in the USA in 2014 and in the EU in 2013. Alemtuzumab is a CD52-directed cytolytic monoclonal antibody; it reduces the levels of circulating $\mathrm{T}$ and $\mathrm{B}$ lymphocytes. Alemtuzumab is indicated for adults with RRMS with active disease. It is administered as an IV infusion for two initial treatment courses (first treatment course: 5 consecutive days; second treatment course: administration on 3 consecutive days 
12 months after first course) and subsequent additional treatment courses after at least 1 year from the second infusion, if required [28]. In clinical trials, alemtuzumab significantly reduced ARR and new brain lesions as compared to IFN $\beta$-1a over 2 years in patients with RRMS $[9,10]$.

The most common adverse event reported with alemtuzumab is infusion-related reactions, for which monitoring and administration of symptomatic treatment are recommended [45]. Autoimmune thyroiditis, a serious adverse event, is seen in approximately $30 \%$ of patients taking alemtuzumab. Autoimmune thyroiditis is typically at its peak during the third year of treatment with alemtuzumab. Clinical vigilance along with monitoring of thyroid-stimulating hormone (TSH) and thyroid antibodies every 3 months is recommended as a precautionary measure for autoimmune thyroiditis. Other autoimmune adverse events associated with alemtuzumab include immune thrombocytopenia and glomerulonephritis. Alemtuzumab also increases the risk of malignancies, including thyroid cancer [27]. A risk management plan which entails clinical vigilance and monthly laboratory monitoring for platelets, renal function testing, and urinalysis is recommended. Recently, the US Food and Drug Administration (FDA) has issued a notice citing rare but serious cases of stroke and tears in the lining of head and neck reported in 13 patients receiving alemtuzumab. According to the FDA, this adverse event can lead to permanent disability and even death (FDA Safety Announcement. Drug safety and availability-FDA warns about rare but serious risks of stroke and blood vessel wall tears with multiple sclerosis drug Lemtrada [12] [WWW Document] 2018). Furthermore, infrequent cases of listeria infection have been reported with alemtuzumab, for which use of prophylactic antibiotics with each course of infusion is recommended by experts [40]. Because of its safety profile, the use of alemtuzumab is restricted to patients with either highly active disease or patients who have had an inadequate response to previous DMDs indicated for the treatment for MS [27].

\section{Cladribine tablets}

Cladribine tablets are orally administered drugs, approved in the EU in 2017. Oral cladribine has not yet been approved for RMS. Cladribine is a structural analogue of deoxyadenosine; preferential accumulation of cladribine phosphates interferes with DNA synthesis and repair, ultimately resulting in DNA strand breaks and cell death [26]. Cladribine is given orally as tablets in two short courses 1 year apart. No active treatment is required in year 3 and 4 . Cladribine tablets are indicated for adults with highly active RMS as defined by clinical and radiological features [30]. In clinical trials, cladribine tablets significantly reduced the ARR, probability of disability progression, and brain lesions as compared to placebo over 96 weeks in patients with RRMS [11, 16, 17]. The most common adverse event associated with cladribine tablets is lymphopenia [30]. A resultant depletion in the body's immune cells can increase the risk of infections and malignancies. Patients with lymphocyte counts below 500 cells/ $\mathrm{mm}^{3}$ should be actively monitored for signs and symptoms suggestive of infections [30]. Among MS patients treated with cladribine (1976 patients), no case of PML has been reported [30]. As cladribine tablets have been approved recently, real-world evidence data is limited $[48]^{1}$.

\section{Ocrelizumab}

Ocrelizumab is a recombinant humanized monoclonal antibody, approved in the USA in 2017 and in the EU in 2018. Ocrelizumab binds to the cell surface antigen CD20 and selectively reduces the number and function of $B$ cells. Ocrelizumab is indicated in adults with active relapsing or primary progressive forms of MS. It is administered as an IV infusion [37]. In clinical trials, ocrelizumab significantly reduced the ARR, probability of disability progression, and brain lesions as compared to IFN $\beta$-1a over 96 weeks in patients with relapsing MS [20]. The most common and important adverse events

\footnotetext{
1 Cladribine described across the article refers to the oral formulation, Cladribine tablets.
} 
associated with ocrelizumab are infusion-related reactions and infections [37]. As ocrelizumab is a recently approved drug, limited real-world data are available [34].

\section{EXPERT OPINION}

A workshop that included a total of nine MS experts from the Gulf region (Oman, United Arab Emirates, Qatar, Bahrain, and Kuwait) was organized to discuss individual opinions on the use of DMDs in clinical practice. The experts were chosen to be part of the advisory board based on their years of clinical experience in treating MS.

Before the workshop, a panel of these experts reviewed literature that included results of pivotal trials, meta-analyses, real-world evidence studies, and opinions/notifications of the licensing authorities (FDA/European Medicines Agency). The panel selected five DMDs (natalizumab, fingolimod, alemtuzumab, cladribine tablets, and ocrelizumab) and several criteria pertaining to these DMDs that should be discussed in the workshop, in order to reach an opinion on the use of high-efficacy DMDs in MS patients. These criteria were related to efficacy, safety, and convenience, including monitoring and adherence.

In the workshop, all the experts were first presented with latest information about the selected five DMDs. Following this presentation, questions were presented to the experts as part of a voting process. The questions ranged from efficacy of various DMDs, to those analyzing their safety and convenience. Experts used an online voting application/web-based audience response system from their smartphones and clicked the most appropriate responses based on their clinical experience.
The compiled responses were shown in real time on their smartphone screens. This was followed by a discussion to validate their response. If there was a change of opinion based on the discussion, a re-voting was done.

For an efficacy attribute ("reduces disease activity overall"), the experts ranked the DMDs in order (Table 1).

The experts also rated the DMDs based on safety (Table 2) and convenience (Table 3) attributes by giving a ranking out of 10 . Natalizumab scored highest for "availability of longterm safety data"; and cladribine tablets for "low risk of malignancy", "good benefit vs. risk profile", "good short- and long-term safety profile", and "low risk of PML". Ocrelizumab scored highest for being "relatively well tolerated". Regarding the convenience attributes, cladribine tablets scored highest for "convenient route and dosing schedule" and "low monitoring burden", while alemtuzumab scored highest for "good patient compliance". Overall, for the safety and convenience attributes, there was no single drug which scored highest for all the attributes, and the scoring varied based on the attribute.

\section{DISCUSSION}

The opinions and scorings discussed in this review are based on years of clinical experience regarding the usage of DMDs for MS treatment by Gulf region experts. No single drug scored highest for all the attributes, as the preference for the drugs varied based on the efficacy, safety, and convenience attributes. Alemtuzumab was ranked highest for 'reducing overall disease activity', while cladribine tablets scored highest for 'good benefit vs. risk profile'. For convenience attributes, oral DMDs

Table 1 DMD ranking based on efficacy attribute 'reduces disease activity overall' by experts

\begin{tabular}{llllll}
\hline Efficacy attribute & Ranking & & & \\
\cline { 2 - 6 } & $\mathbf{1}$ & $\mathbf{2}$ & $\mathbf{3}$ & $\mathbf{4}$ & $\mathbf{5}$ \\
\hline Reduces disease activity overall & Alemtuzumab & Cladribine tablets & Ocrelizumab & Natalizumab & Fingolimod \\
\hline
\end{tabular}

$D M D$ disease-modifying drug 
Table 2 DMD ranking on safety attributes by experts (higher scores indicate better ranking)

\begin{tabular}{|c|c|c|c|c|c|}
\hline \multirow[t]{2}{*}{ Safety attributes } & \multicolumn{5}{|l|}{ Scoring } \\
\hline & $\begin{array}{l}\text { Cladribine } \\
\text { tablets }\end{array}$ & Fingolimod & Natalizumab & Ocrelizumab & $\overline{\text { Alemtuzumab }}$ \\
\hline Availability of long-term safety data & 7.5 & 6.5 & 8.1 & 7.2 & 7.2 \\
\hline Low risk of malignancy & 7.3 & 6.6 & 6.4 & 6.8 & 5.8 \\
\hline Good benefit vs. risk profile & 7.4 & 5.7 & 7.3 & 6.9 & 6.2 \\
\hline $\begin{array}{l}\text { Good short- and long-term safety } \\
\text { profile }\end{array}$ & 7.7 & 5.8 & 6.7 & 6.8 & 5.8 \\
\hline Low risk of PML & 7.9 & 5.9 & 5.4 & 7.2 & 6.8 \\
\hline Relatively well tolerated & 7.5 & 6.8 & 7.0 & 7.8 & 6.2 \\
\hline
\end{tabular}

$D M D$ disease-modifying drug, $P M L$ progressive multifocal leukoencephalopathy

Table 3 DMD ranking on convenience attributes by experts (higher scores indicate better ranking)

\begin{tabular}{|c|c|c|c|c|c|}
\hline \multirow[t]{2}{*}{ Convenience attributes } & \multicolumn{5}{|l|}{ Scoring } \\
\hline & Cladribine tablets & Fingolimod & Natalizumab & Ocrelizumab & $\overline{\text { Alemtuzumab }}$ \\
\hline Convenient route and dosing schedule & 8.7 & 8.0 & 7.5 & 7.8 & 8.1 \\
\hline Good patient compliance & 8.0 & 7.3 & 8.0 & 7.8 & 8.3 \\
\hline Low monitoring burden & 8.0 & 6.7 & 7.5 & 7.2 & 5.9 \\
\hline
\end{tabular}

$D M D$ disease-modifying drug

including cladribine tablets and fingolimod were more favored for their convenient route and dosing schedule and low monitoring burden.

The expert panel discussed the difficulty in directly comparing the efficacy and safety of DMDs for RRMS. There is a difference between the clinical trials of new and old DMDs in different patient populations; for instance, baseline ARR in both treatment and control arms is different in these trials. Since diagnostic techniques for MS have evolved over the years, it is likely that these clinical trials also differ in the type of MS patient populations studied. Additionally, there are methodological differences (e.g., use of different comparators) across these clinical trials. More importantly, efficacy and safety data available for each DMD differs based on timespan of the DMD in the market; for example, plenty of long-term post-marketing data are available for natalizumab, but no long- term data are available for the recently approved ocrelizumab and cladribine tablets. In the absence of head-to-head clinical trials for the newer DMDs, comparative efficacy analyses using propensity score matching may be a valid approach, despite its potential bias. Furthermore, clinical experience with these DMDs is also valuable in corroborating the findings from clinical studies and shaping future opinions regarding DMDs' perceived benefits.

All available DMDs have demonstrated through clinical trials that they reduce the frequency and severity of relapses, reduce the development of new brain lesions, and slow the progression of disability in relapsing forms of MS, to varying extents. Ocrelizumab is the only drug which has demonstrated efficacy in both relapsing and primary progressive forms of MS; alemtuzumab and cladribine have not been known to be used for primary-progressive MS. Considering overlapping efficacy profiles of the 
drugs, safety and convenience attributes based on individual risk factors and patient preferences are an important part of treatment decision-making.

The definition of high-efficacy DMDs was used by MS experts in order to guide the treating neurologists on how to manage patients with highly active disease. Although there is no established consensus on the definition of highly active patients, it is generally accepted that those who have two or more relapses in 1 year or those who failed (or had suboptimal response) first-line therapies are considered adequate candidates for high-efficacy DMDs. Alemtuzumab and cladribine tablets are drugs for which patients who had a sub-optimal response were assessed in a clinical trial [10]. On contrary, natalizumab and fingolimod have not been tested in such a population in clinical trials, but yet these drugs are used in such patients in clinical practice with good efficacy [14]. Posthoc analysis for ocrelizumab [21, 25] and cladribine [18] showed similar results in patients with suboptimal response; however, these results should be interpreted with caution. Considering the high scores given to ocrelizumab and cladribine tablets in the workshop for efficacy, safety, and convenience attributes, they seem to be promising drugs in the treatment of highly active MS patients. However, long-term data for these newly approved DMDs are needed to show the presumed sustained effectiveness in such patient group.

The safety of DMDs was considered a very important attribute by the panel, especially with regards to selection of these DMDs for a specific group of patients. For example, it is advised to not use fingolimod in MS patients with cardiac disease or diabetic retinopathy. Similarly, patients with high anti-JCV titers (>1.5) are advised not to use natalizumab, while alemtuzumab should not be used in MS patients who have other autoimmune disorders. Long-term safety data of the newly approved DMDs, such as ocrelizumab and cladribine are not yet available; hence vigilance should be done when using such DMDs.

Patient's convenience is another attribute, which plays an important role while discussing treatment options with the patient. Certainly, oral DMDs such as fingolimod and cladribine tablets seem to be a very attractive option to patients; however, a few physicians and patients may consider DMDs that have less frequent dosing as a more convenient option; such DMDs include alemtuzumab (yearly course for 2 years) and ocrelizumab (6-month course). Cladribine tablets offer both, benefits of less frequent dosing and the oral route, and this may explain why it was scored high by the panel. When discussing convenience, the burden of monitoring may play an important role, as DMDs with frequent laboratory monitoring (e.g. alemtuzumab) may be less appealing to patients and sometimes physicians.

\section{CONCLUSION}

All DMDs available for the treatment of MS have benefits and risks, which should be considered while discussing the treatment plan with the patient. It is important to have a personalized approach based on the risk-benefit assessment for each case. Common considerations while choosing treatments include effectiveness, side effects/safety, and convenience/ route of administration.

\section{ACKNOWLEDGEMENTS}

The expert group described here met during a meeting organized by and funded by Merck Serono Middle East FZ LTD, an affiliate of Merck KGaA, Darmstadt, Germany. Editorial assistance was provided by Dr. Rupali Bahri (Medcytes, Dubai) and funded by Merck Serono Middle East FZ LTD. We thank our colleague Prof. Jaume Sastre-Garriga (Neurology-Neuroimmunology Department \& Neurorehabilitation Unit Multiple Sclerosis Centre of Catalonia [Cemcat]), who provided insight and expertise that greatly assisted the moderation of the workshop. Merck Serono Middle East FZ LTD will sponsor the journal article processing charge.

Funding. Merck Serono Middle East FZ LTD funded the study and the article processing 
charges. All authors had full access to all of the data in this article and take complete responsibility for the integrity of the data and accuracy of the data analysis.

Authorship. All named authors meet the International Committee of Medical Journal Editors (ICMJE) criteria for authorship for this article, take responsibility for the integrity of the work as a whole, and have given their approval for this version to be published.

Disclosures. Amir Boshra is an employee of Merck Serono Middle East FZ LTD. All authors acted as honorary consultants to Merck Serono Middle East FZ LTD as part of the advisory board.

Compliance with Ethics Guidelines. This article does not contain any studies with human participants or animals performed by any of the authors.

Data Availability. The datasets during and/ or analyzed during the current study are available from the corresponding author on reasonable request.

Open Access. This article is distributed under the terms of the Creative Commons Attribution-NonCommercial 4.0 International License (http://creativecommons.org/licenses/ by-nc/4.0/), which permits any noncommercial use, distribution, and reproduction in any medium, provided you give appropriate credit to the original author(s) and the source, provide a link to the Creative Commons license, and indicate if changes were made.

\section{REFERENCES}

1. Bar-Or A. The immunology of multiple sclerosis. Semin Neurol. 2008;28:29-45. https://doi.org/10. 1055/s-2007-1019124.

2. Berger JR, Cree BA, Greenberg B, Hemmer B, Ward BJ, Dong VM, Merschhemke M. Progressive multifocal leukoencephalopathy after fingolimod treatment. Neurology. 2018;90:e1815-21. https://doi. org/10.1212/WNL.0000000000005529.
3. Bezabeh S, Flowers CM, Kortepeter C, Avigan M. Review article: clinically significant liver injury in patients treated with natalizumab (TYSABRI ${ }^{\mathrm{TM}}$ ). Aliment Pharmacol Ther. 2010. https://doi.org/10. 1111/j.1365-2036.2010.04262.x.

4. Brinkmann V. FTY720 (fingolimod) in multiple sclerosis: therapeutic effects in the immune and the central nervous system. $\mathrm{Br} \mathrm{J}$ Pharmacol. 2009;158:1173-82. https://doi.org/10.1111/j.14765381.2009.00451.x.

5. Brinkmann V, Billich A, Baumruker T, Heining $\mathrm{P}$, Schmouder R, Francis G, Aradhye S, Burtin P. Fingolimod (FTY720): discovery and development of an oral drug to treat multiple sclerosis. Nat Rev Drug Discov. 2010;9:883-97. https://doi.org/10. 1038/nrd3248.

6. Cheng Z, Zhang J, Liu H, Li Y, Zhao Y, Yang E. Central nervous system penetration for small molecule therapeutic agents does not increase in multiple sclerosis- and Alzheimer's disease-related animal models despite reported blood-brain barrier disruption. Drug Metab Dispos. 2010;38:1355-61. https://doi.org/10.1124/dmd.110.033324.

7. Clanet MC, Wolinsky JS, Ashton RJ, Hartung H-P, Reingold SC. Risk evaluation and monitoring in multiple sclerosis therapeutics. Mult Scler Houndmills Basingstoke Engl. 2014;20:1306-11. https:// doi.org/10.1177/1352458513513207.

8. Cohen JA, Barkhof F, Comi G, Hartung H-P, Khatri BO, Montalban X, Pelletier J, Capra R, Gallo P, Izquierdo G, Tiel-Wilck K, de Vera A, Jin J, Stites T, $\mathrm{Wu} \mathrm{S}$, Aradhye S, Kappos L. Oral fingolimod or intramuscular interferon for relapsing multiple sclerosis. N Engl J Med. 2010;362:402-15. https:// doi.org/10.1056/NEJMoa0907839.

9. Cohen JA, Coles AJ, Arnold DL, Confavreux C, Fox EJ, Hartung H-P, Havrdova E, Selmaj KW, Weiner HL, Fisher E, Brinar VV, Giovannoni G, Stojanovic M, Ertik BI, Lake SL, Margolin DH, Panzara MA, Compston DAS, CARE-MS I Investigators. Alemtuzumab versus interferon beta $1 \mathrm{a}$ as first-line treatment for patients with relapsing-remitting multiple sclerosis: a randomised controlled phase 3 trial. Lancet Lond Engl. 2012;380:1819-28. https:// doi.org/10.1016/S0140-6736(12)61769-3.

10. Coles AJ, Twyman CL, Arnold DL, Cohen JA, Confavreux C, Fox EJ, Hartung H-P, Havrdova E, Selmaj KW, Weiner HL, Miller T, Fisher E, Sandbrink R, Lake SL, Margolin DH, Oyuela P, Panzara MA, Compston DAS. Alemtuzumab for patients with relapsing multiple sclerosis after disease-modifying therapy: a randomised controlled phase 3 trial. Lancet. 2012;380:1829-39. https://doi.org/10.1016/ S0140-6736(12)61768-1. 
11. Comi G, Cook S, Rammohan K, Soelberg Sorensen P, Vermersch P, Adeniji AK, Dangond F, Giovannoni G. Long-term effects of cladribine tablets on MRI activity outcomes in patients with relapsing-remitting multiple sclerosis: the CLARITY extension study. Ther Adv Neurol Disord. 2018. https://doi.org/10.1177/1756285617753365.

12. FDA Safety Announcement. Drug safety and availability-FDA warns about rare but serious risks of stroke and blood vessel wall tears with multiple sclerosis drug lemtrada (alemtuzumab) [WWW Document]. 2018. https://www.fda.gov/Drugs/ DrugSafety/ucm624247.htm. Accessed 10 Jan 2019.

13. Fonseca J. Fingolimod real world experience: efficacy and safety in clinical Practice. Neurosci J. 2015. https://doi.org/10.1155/2015/389360.

14. Freedman MS. Treatment options for patients with multiple sclerosis who have a suboptimal response to interferon- $\beta$ therapy. Eur J Neurol. 2014;21:377e20. https://doi.org/10.1111/ene.12299.

15. Gilenya SPC. Novartis pharmaceuticals UK Ltd, Surrey, UK. European Medicines Agency. [WWW Document]. 2018. https://www.medicines.org.uk/ emc/product/4545. Accessed 12 Feb 2018.

16. Giovannoni G, Comi G, Cook S, Rammohan K, Rieckmann P, Sørensen PS, Vermersch P, Chang P, Hamlett A, Musch B, Greenberg SJ. A placebo-controlled trial of oral cladribine for relapsing multiple sclerosis. N Engl J Med. 2010;362:416-26. https:// doi.org/10.1056/NEJMoa0902533.

17. Giovannoni G, Soelberg Sorensen P, Cook S, Rammohan K, Rieckmann P, Comi G, Dangond F, Adeniji AK, Vermersch P. Safety and efficacy of cladribine tablets in patients with relapsing-remitting multiple sclerosis: results from the randomized extension trial of the CLARITY study. Mult Scler Houndmills Basingstoke Engl. 2017. https://doi. org/10.1177/1352458517727603.

18. Giovannoni G, Soelberg Sorensen P, Cook S, Rammohan KW, Rieckmann P, Comi G, Dangond F, Hicking C, Vermersch P. Efficacy of cladribine tablets in high disease activity subgroups of patients with relapsing multiple sclerosis: a post hoc analysis of the CLARITY study. Mult Scler Houndmills Basingstoke Engl. 2018. https://doi.org/10.1177/ 1352458518771875 .

19. González-Suarez I, Rodríguez de Antonio L, Orviz A, Moreno-García S, Valle-Arcos MD, Matias-Guiu JA, Valencia C, Jorquera Moya M, Oreja-Guevara C. Catastrophic outcome of patients with a rebound after natalizumab treatment discontinuation. Brain Behav. 2017. https://doi.org/10.1002/brb3.671.

20. Hauser SL, Bar-Or A, Comi G, Giovannoni G, Hartung H-P, Hemmer B, Lublin F, Montalban X, Rammohan KW, Selmaj K, Traboulsee A, Wolinsky JS, Arnold DL, Klingelschmitt G, Masterman D, Fontoura P, Belachew S, Chin P, Mairon N, Garren $\mathrm{H}$, Kappos L. Ocrelizumab versus interferon beta-1a in relapsing multiple sclerosis. $\mathrm{N}$ Engl J Med. 2017;376:221-34. https://doi.org/10.1056/ NEJMoa1601277.

21. Havrdová E, Arnold DL, Bar-Or A, Comi G, Hartung H-P, Kappos L, Lublin F, Selmaj K, Traboulsee A, Belachew S, Bennett I, Buffels R, Garren H, Han J, Julian L, Napieralski J, Hauser SL, Giovannoni G. No evidence of disease activity (NEDA) analysis by epochs in patients with relapsing multiple sclerosis treated with ocrelizumab vs interferon beta-1a. Mult Scler J Exp Transl Clin. 2018. https://doi.org/ $10.1177 / 2055217318760642$.

22. Kantor D, Johnson K, Vieira MC, Signorovitch J, Li N, Gao W, Koo V, Duchesneau E, Herrera V. Realworld persistence with fingolimod for the treatment of multiple sclerosis: a systematic review and meta-analysis. J Neurol Sci. 2018;388:168-74. https://doi.org/10.1016/j.jns.2018.03.018.

23. Kappos L, Radue E-W, O'Connor P, Polman C, Hohlfeld R, Calabresi P, Selmaj K, Agoropoulou C, Leyk M, Zhang-Auberson L, Burtin P. A placebocontrolled trial of oral fingolimod in relapsing multiple sclerosis. N Engl J Med. 2010;362:387-401. https://doi.org/10.1056/NEJMoa0909494.

24. Khimani KS, Foroozan R. Central serous chorioretinopathy associated with fingolimod treatment. J Neuroophthalmol. 2018;38:337. https://doi.org/ 10.1097/WNO.0000000000000592.

25. Leist TP, Reder AT, Bermel R, Weinstock-Guttman B, Freedman MS, Cutter G, Stankiewicz J, Zheng H, Musch B, Csoboth C, Wolinsky JS. Year one interim analysis results of the phase IIIb CHORDS study evaluating ocrelizumab effectiveness and safety in patients with relapsing-remitting multiple sclerosis who had suboptimal response with prior diseasemodifying treatments [WWW Document]. 2018. http://onlinelibrary.ectrims-congress.eu/ectrims/ 2018/ectrims-2018/228479/thomas.p.leist.year.one. interim.analysis.results.of.the.phase.iiib.chords.html. Accessed 12 Jan 2019.

26. Leist TP, Weissert R. Cladribine: mode of action and implications for treatment of multiple sclerosis. 
Clin Neuropharmacol. 2011;34:28-35. https://doi. org/10.1097/WNF.0b013e318204cd90.

27. Lemtrada PI. Genzyme Corporation, MA, USA. Food and Drug Administration; 2018.

28. Lemtrada SPC. Genzyme therapeutics, Oxfordshire, UK. European Medicines Agency. [WWW Document]. 2018. https://www.medicines.org.uk/emc/ product/5409. Accessed 12 Feb 2018.

29. Markowitz CE. Multiple sclerosis update. Am J Manag Care. 2013;19:s294-300.

30. Mavenclad SPC. Merck Serono Europe Limited, London, UK. European Medicines Agency. [WWW Document]. 2018. https://www.medicines.org.uk/ emc/product/8435/smpc. Accessed 12 Feb 2018.

31. Mehling M, Brinkmann V, Antel J, Bar-Or A, Goebels N, Vedrine C, Kristofic C, Kuhle J, Lindberg RLP, Kappos L. FTY720 therapy exerts differential effects on T cell subsets in multiple sclerosis. Neurology. 2008;71:1261-7. https://doi.org/10.1212/ 01.wnl.0000327609.57688.ea.

32. Menon S, Shirani A, Zhao Y, Oger J, Traboulsee A, Freedman MS, Tremlett H. Characterising aggressive multiple sclerosis. J Neurol Neurosurg Psychiatry. 2013;84:1192-8. https://doi.org/10.1136/ jnnp-2013-304951.

33. Miller DH, Soon D, Fernando KT, MacManus DG, Barker GJ, Yousry TA, Fisher E, O'Connor PW, Phillips JT, Polman CH, Kappos L, Hutchinson M, Havrdova E, Lublin FD, Giovannoni G, Wajgt A, Rudick R, Lynn F, Panzara MA, Sandrock AW, Investigators AFFIRM. MRI outcomes in a placebocontrolled trial of natalizumab in relapsing MS. Neurology. 2007;68:1390-401. https://doi.org/10. 1212/01.wnl.0000260064.77700.fd.

34. Moss B, Utigard E, Baldassari L, Cohen J, Ontaneda D. Real-world experience with ocrelizumab (P6.356). Neurology. 2018;90:P6.356.

35. NICE Pathways. Disease-modifying therapies for multiple sclerosis. 2018.

36. Noseworthy JH, Lucchinetti C, Rodriguez M, Weinshenker BG. Multiple sclerosis. N Engl J Med. 2000;343:938-52. https://doi.org/10.1056/ NEJM200009283431307.

37. Ocrevus SPC. Roche Products Limited, Hertfordshire, UK. European Medicines Agency. [WWW Document]. 2018. https://www.medicines.org.uk/ emc/product/8898. Accessed 12 Feb 2018.

38. Pinschewer DD, Brinkmann V, Merkler D. Impact of sphingosine 1-phosphate modulation on immune outcomes. Neurology. 2011;76:S15-9. https://doi. org/10.1212/WNL.0b013e31820d9596.

39. Polman $\mathrm{CH}, \mathrm{O}^{\prime}$ Connor PW, Havrdova E, Hutchinson M, Kappos L, Miller DH, Phillips JT, Lublin FD, Giovannoni G, Wajgt A, Toal M, Lynn F, Panzara MA, Sandrock AW. A randomized, placebo-controlled trial of natalizumab for relapsing multiple sclerosis. N Engl J Med. 2006;354:899-910. https:// doi.org/10.1056/NEJMoa044397.

40. Rau D, Lang M, Harth A, Naumann M, Weber F, Tumani $\mathrm{H}$, Bayas A. Listeria meningitis complicating alemtuzumab treatment in multiple sclerosis-report of two cases. Int J Mol Sci. 2015;16:14669-76. https:// doi.org/10.3390/ijms160714669.

41. Rice GPA, Hartung H-P, Calabresi PA. Anti-alpha4 integrin therapy for multiple sclerosis: mechanisms and rationale. Neurology. 2005;64:1336-42. https://doi.org/10.1212/01.WNL.0000158329. 30470.D0.

42. Rush CA, MacLean HJ, Freedman MS. Aggressive multiple sclerosis: proposed definition and treatment algorithm. Nat Rev Neurol. 2015;11:379-89. https://doi.org/10.1038/nrneurol.2015.85.

43. Schaeffer J, Cossetti C, Mallucci G, Pluchino S. Chapter 30-Multiple sclerosis. In: Zigmond MJ, Rowland LP, Coyle JT, editors. Neurobiology of brain disorders. San Diego: Academic Press; 2015. p. 497-520. https://doi.org/10.1016/B978-0-12398270-4.00030-6.

44. Sempere AP, Berenguer-Ruiz L, Feliu-Rey E. Rebound of disease activity during pregnancy after withdrawal of fingolimod. Eur J Neurol. 2013;20:e109-10. https://doi.org/10.1111/ene. 12195.

45. Sharrack B, Mayer L, Coles A, Hartung H-P, Havrdova E, Selmaj K, Margolin D, Compston A. Management of adverse reactions to alemtuzumab infusion. $\mathrm{J}$ Neurol Neurosurg Psychiatry. 2015;86:e4. https://doi.org/10.1136/jnnp-2015312379.119 .

46. Singer BA. The role of natalizumab in the treatment of multiple sclerosis: benefits and risks. Ther Adv Neurol Disord. 2017;10:327-36. https://doi.org/10. $1177 / 1756285617716002$.

47. Thompson SAJ, Jones JL, Cox AL, Compston DAS, Coles AJ. B-cell reconstitution and BAFF after alemtuzumab (Campath-1H) treatment of multiple sclerosis. J Clin Immunol. 2010;30:99-105. https:// doi.org/10.1007/s10875-009-9327-3.

48. Trial ID: NCT01013350. Prospective observational long-term safety registry of multiple sclerosis patients who have participated in cladribine 
clinical trials-full text view-ClinicalTrials.gov [WWW Document]. 2018. https://clinicaltrials.gov/ ct2/show/NCT01013350. Accessed 14 Dec 2018.

49. Tysabri SPC. Biogen Idec Ltd, Berkshire, UK. European Medicines Agency. [WWW Document]. 2018. https://www.medicines.org.uk/emc/product/222. Accessed 12 Feb 2018.

50. Vargas WS, Perumal JS. Fingolimod and cardiac risk: latest findings and clinical implications. Ther Adv
Drug Saf. 2013;4:119-24. https://doi.org/10.1177/ 2042098613481023.

51. Winkelmann A, Loebermann M, Reisinger EC, Hartung H-P, Zettl UK. Disease-modifying therapies and infectious risks in multiple sclerosis. Nat Rev Neurol. 2016;12:217-33. https://doi.org/10.1038/ nrneurol.2016.21. 